Research Article

\title{
Effect of Aging on the Rheological and Molecular Weight Distribution of Asphalt Binder Treated with Polyphosphoric Acid
}

\author{
Tao Ma, ${ }^{1}$ Kai Yang $\mathbb{D}^{2}$ Rui Li $\mathbb{D}^{2},{ }^{2}$ and Jiujian Shen $^{3}$ \\ ${ }^{1}$ Tong Chuan Highway Engineering Construction Headquarters Office, Tong Chuan, Shaanxi 727000, China \\ ${ }^{2}$ School of Highway, Chang'an University, Xi'an, Shaanxi 710064, China \\ ${ }^{3}$ Shaanxi Provincial Expressway Construction Group Co., Xi'an, Shaanxi 710065, China \\ Correspondence should be addressed to Kai Yang; kaiyang@chd.edu.cn
}

Received 16 March 2021; Revised 11 May 2021; Accepted 9 August 2021; Published 17 August 2021

Academic Editor: Ivan Giorgio

Copyright (C 2021 Tao Ma et al. This is an open access article distributed under the Creative Commons Attribution License, which permits unrestricted use, distribution, and reproduction in any medium, provided the original work is properly cited.

\begin{abstract}
Asphalt binder behaves as a viscoelastic material and its inherit performance is dominated by rheological and chemical properties. Aging of asphalt binder is a prominent distress for long-term in-service asphalt pavement. In this work, the effect of aging on base asphalt modified by polyphosphoric acid (PPA) has been investigated. For the objective, virgin asphalt binder was modified by various dosages of PPA, styrene-butadiene-styrene (SBS), and PPA/SBS compound modification. The short- and long-term aging processes were simulated by Rolling Thin-Film Oven Test (RTFOT) and Pressure Aging Vessel (PAV) procedure. Rheological property of five aged modified binders was evaluated by the Dynamic Shear Rheometer (DSR). Meanwhile, gel permeation chromatography (GPC) was conducted to measure the molecular weight distribution and dispersion coefficient during the aging process. The high-temperature stiffness of PPA polymer binders is slightly higher than that of SBS and PPA/SBS compound modified asphalts. The aging ratio and molecular weight analysis verify the lower thermal-oxidative susceptibility of PPA/SBS compound modified asphalts. This study offers an understanding for the promotion and application of PPA modifier.
\end{abstract}

\section{Introduction}

Thermal-oxidative aging is a complicated process and induces damage of asphalt pavement during a long service life. This phenomenon has caused the adverse impact on the flexibility and durability of pavement. The main damage caused by aging at intermittent temperature is longitudinal cracking and the decrease of fatigue life for a long duration of pavement service [1-4].

To mitigate the premature damage related to the aged asphalt materials, it is generally acceptable to utilize modified asphalts to improve damage resistance since the strategic highway research program (SHRP) in the 1990s. The aging resistance of asphalt binder can be improved by using SBS, epoxy resin, styrene-butadiene rubber (SBR), and waste rubber as modifiers. Polymer modifiers play an active role in preventing the premature damage caused by long-term aging [5-7].

However, utilizing polymer modified asphalt during construction process cost more than base asphalt. For pavement engineers, finding an economic and effective way to modify the binder with better antiaging performance is an important task $[8,9]$. The preparation of PPA modified asphalt does not require special asphalt equipment. No special temperature is required and the preparation process is simple. The price of PPA modified asphalt is relatively cheap, only accounting for $20 \mathrm{wt} \%-25 \mathrm{wt} \%$ of SBS modified asphalt. Therefore, it is of great economic value to use PPA modified asphalt. It has been reported that adding PPA to base asphalt can increase its softening point, viscosity, and needle penetration [10-13]. The application of PPA can change the high-temperature PG grade to next higher level, and the critical cracking temperature of asphalt can also rise $3-5^{\circ} \mathrm{C}[14]$. Some studies have shown that PPA can take the place of some SBS components in polymer modified asphalt $[15,16]$. A small amount of PPA has the similar effect on the property of SBS polymer binders [17-19]. However, the aging performance, modification mechanism, and chemical property of PPA modified asphalt are uncertain. There are few studies on antiaging property of PPA modified asphalt. 
Heating of asphalt mixture during production or construction process and external environment factors (i.e., temperature, light, rain, and traffic load) on asphalt pavement during long service life lead to asphalt mixture aging. The two processes are so-called short-term and long-term aging [20]. RTFOT and PAV test are the most common methods to simulate the aging procedure [21]. Aging can notably influence the rheological property of asphalt binder, resulting in hardening of asphalt pavement and reducing the service life [22]. The aging performance can be characterized by rheological/physical performance before and after aging $[9,23]$. GPC can be utilized to separate solution molecules into different sizes. It can clearly describe the molecular weight distribution of solution in medium [24-28]. Some studies have shown the molecular weight and distribution of SBS modified asphalt under different aging conditions by GPC [29]. However, there are fewer research studies on the aging mechanism of PPA modified asphalt.

Due to the lack of incorporating polymer binders into initial SHRP work, some specifications are only focused on unmodified, petroleum-based asphalts (e.g., AASHTO M320 Performance-Grade specification). Polymer asphalts have been widely used in pavement engineering in recent years. The formulation and manufacture of asphalt binders have undergone great changes since the development of the PG asphalt binder specifications formulated by SHRP. Recently, National Cooperative Highway Research Program (NCHRP) 9-60 project, "Addressing Impacts of Changes in Asphalt Binder Formulation and Manufacture on Pavement Performance through Changes in Asphalt Binder Specifications," can provide additional information about the performance-related properties of modified asphalt binder.

In the study, RTFOT and PAV aging procedures were selected and the influence of different aging modes on the rheological property of polymer binders was studied. The effect of PPA dosage on the aging characterization (i.e., aging ratio in this work) was also analyzed for modified asphalt binder. GPC was selected to analyze the molecular weight and dispersion coefficient in the aging process. This study can provide some theoretical basis for the application of PPA modifier.

\section{Materials and Methods}

2.1. Materials. To study the effect of different PPA dosages on the antiaging property, five different modified asphalts were prepared including $1.0 \mathrm{wt} \%$ PPA (weight of base asphalt), $1.5 \mathrm{wt} \%$ PPA, $3.5 \mathrm{wt} \%$ SBS modified asphalt, $1.0 \mathrm{wt} \%$ $\mathrm{PPA}+3.5 \mathrm{wt} \% \mathrm{SBS}$, and $1.5 \mathrm{wt} \% \mathrm{PPA}+3.5 \mathrm{wt} \% \mathrm{SBS}$ compound modified asphalt. At the same time, $3.5 \mathrm{wt} \%$ SBS modified asphalt was used as a control sample of polymer binder.

The base asphalt binder SK90 and ZH90 was modified in this study. YH791 SBS modifier of Yueyang Sinopec was used in the test. Polyphosphoric acid was utilized as a modifier with the $\mathrm{H}_{2} \mathrm{PO}_{3}$ content of $105 \mathrm{wt} \%$.

2.2. Sample Preparation. The process of sample preparation is shown in Figure 1.
2.3. Aging Performance Test. The short- and long-term aging processes of asphalt binder were simulated by RTFOT and PAV according to the AASHTO T240 and R28. After the two types of aging process, the rheological property of the modified asphalt was studied by DSR (Anton Paar, smartpave-102) at intermediate temperature. The viscoelastic properties were characterized by complex modulus and phase angle of asphalt binder. The two parameters were measured by DSR. Under various aging conditions, the temperature sweep (based on AASHTO T315) was conducted ranging from 20 to $60^{\circ} \mathrm{C}$ with $1^{\circ} \mathrm{C}$ increasing rate per 60 seconds, which can be attributed to obtaining the thermosensitivity and temperature dependence of modified binder. The oscillatory test was conducted at a certain frequency of $10 \mathrm{rad} / \mathrm{s}$ under strain-controlled mode, attributed to simulation of $90 \mathrm{~km} / \mathrm{h}$ traffic speed by the recommendation form SHRP [30]. $8 \mathrm{~mm}$ plate and $2 \mathrm{~mm}$ gap between parallel plates were set up during this test.

Gel permeation chromatography (GPC) is a chromatographic column consisting of polymer solution through porous materials. The polymeric molecule can be separated by different particle sizes. The high polymer in solution exists in the form of random coil, and the polymer molecular size is a certain value. Large polymer molecules can only diffuse into large holes and retain in the column for a short time. The small size of polymer molecules can diffuse into almost all the holes. It will lead to deeper diffusion into the holes and the polymer molecules of smaller size remain in the column for a long time. Therefore, polymer molecules can be separated in sequence according to different molecular weights.

The analytical test of GPC can provide molecular weight distribution of polymer asphalt binder and separate molecules in polymers by size. In this work, the GPC test was conducted for PPA binders of different aging conditions. In the GPC test, test sample was made into $4 \mathrm{mg} / \mathrm{ml}$ asphalttetrahydrofuran solution. The test temperature was $40^{\circ} \mathrm{C}$.

2.4. Rheological Aging Parameter. The antiaging performance of PPA binders can be evaluated by rheological aging index. The test results (fatigue factor $G * \operatorname{Sin} \delta$ at intermediate temperature based on AASHTO M320) were selected to calculate the aging index (AI):

$$
\mathrm{AI}=\frac{\text { aged fatigue factor }- \text { unaged fatigue factor }}{\text { unaged fatigue factor }} \text {. }
$$

The fatigue factor for a given binder at intermittent temperature is not satisfactory to capture the whole effects of embrittlement with aging. At a certain temperature and frequency, $G * \operatorname{Sin} \delta$ can only reflect the variations of viscous portion in the complex modulus domain. Viscoelastic materials can exhibit both viscous and elastic behavior. Complex modulus $\left(G^{*}\right)$ comprises the following two parts: storage modulus $\left(G^{\prime}\right)$ representing the elastic portion associated with the stored energy and loss modulus $\left(G^{\prime \prime}\right)$ illustrating the viscous portion corresponding to the energy dissipated as heat, shown in Figure 2. 


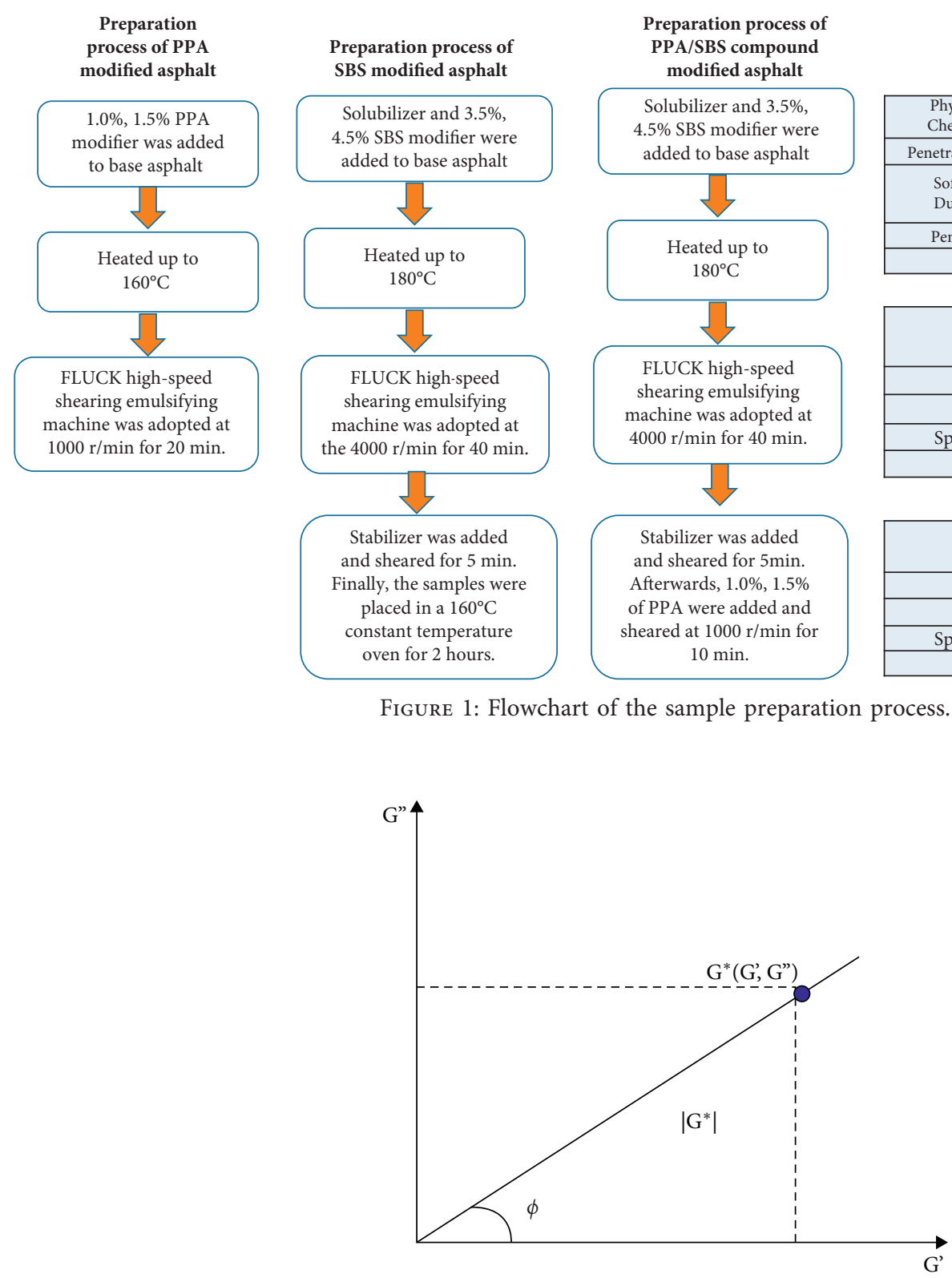

Figure 2: Illustration of $G^{*}$ in complex plane.

\section{Results and Discussions}

\subsection{Rheological Analysis of the Aged Materials}

3.1.1. Effect of Aging on Binder Stiffness. Figure 3 shows that the complex modulus of five different modified binders increased significantly after short- and long-term aging procedure. $G^{*}$ in current superpave PG system is an indicator of binder's stiffness for a given loading history. At different temperatures of $1.0 \mathrm{wt} \%$ PPA, the $\mathrm{G}_{\mathrm{RTFOT}}^{*} / \mathrm{G}_{\text {unaged }}^{*}$ ratios are within 1.9-2.3 after short-term aging, whereas the $\mathrm{G}_{\mathrm{RTFOT}}^{*} / \mathrm{G}_{\text {unaged }}^{*}$ ratios of $1.5 \mathrm{wt} \%$ PPA modified asphalt are from 1.7 to 2.1. At a certain temperature, the modulus increasing multiple of $1.0 \mathrm{wt} \%$ PPA was always greater than $1.5 \mathrm{wt} \%$ PPA modified asphalt. For the five modified binders, the aging modulus ratio $\mathrm{G}_{\mathrm{PAV}}^{*} / \mathrm{G}_{\mathrm{RTFOT}}^{*}$ was greater than
$\mathrm{G}_{\mathrm{RTFOT}}^{*} / \mathrm{G}_{\text {unaged }}^{*}$, indicating a larger discrepancy between RTFOT and PAV aging conditions. Especially for PPA and SBS compound modified binder, the aging modulus ratio of $\mathrm{G}_{\mathrm{PAV}}^{*} / \mathrm{G}_{\mathrm{RTFOT}}^{*}$ was higher in Figures 3(c) and 3(d), which can be attributed to the sensibility of different aging level.

Utilizing a colloidal model can characterize the chemical property of asphalt binders, which is comprised of asphaltene phase dispersed in maltene phase [31]. The mechanism of aging-induced embrittlement is associated with the volatility of light oil in the maltene phase and partial transition from maltene into asphaltene content, which leads to an increase in the asphaltene content and a decrease in the maltene content [22]. Asphalt became hard and modulus increased in the aging process as a result of the migration of asphalt component, as described in Figure 3. The four 


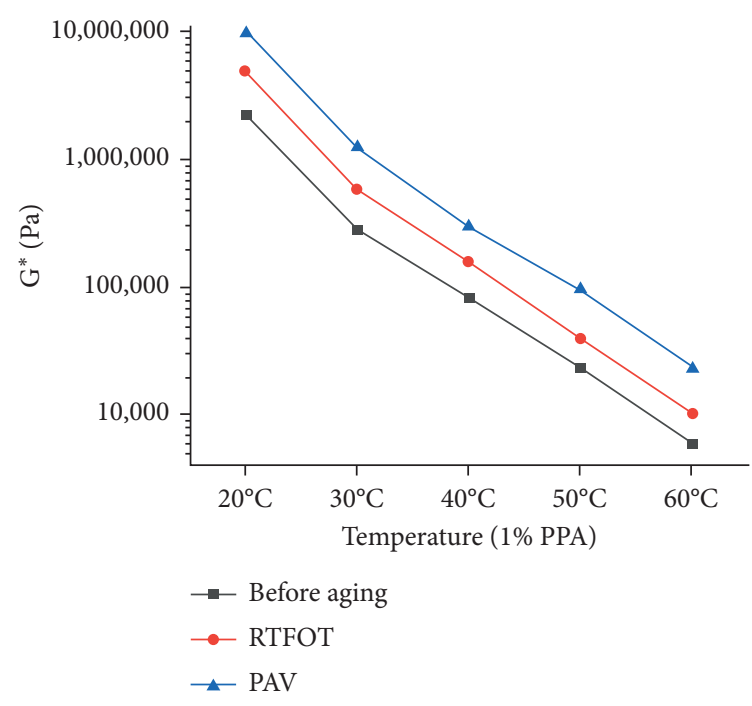

(a)

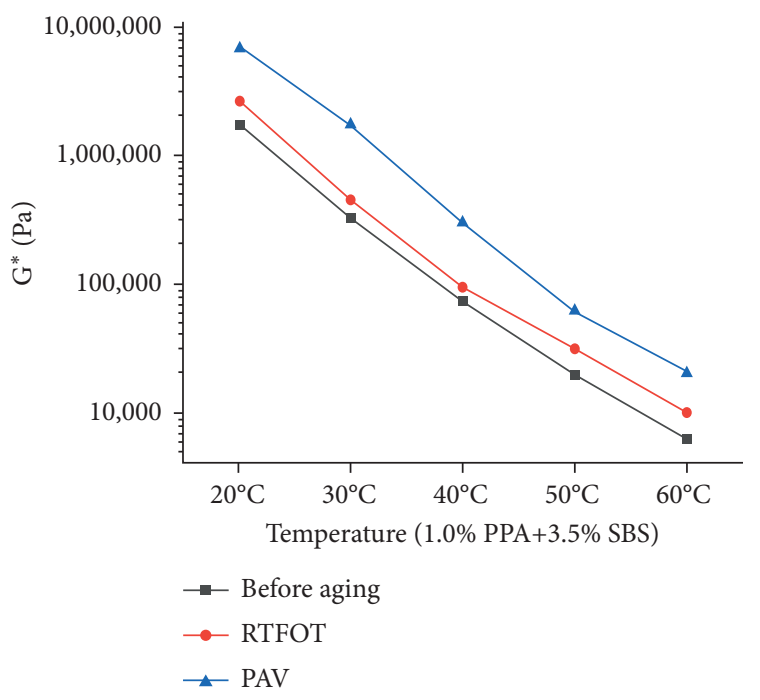

(c)

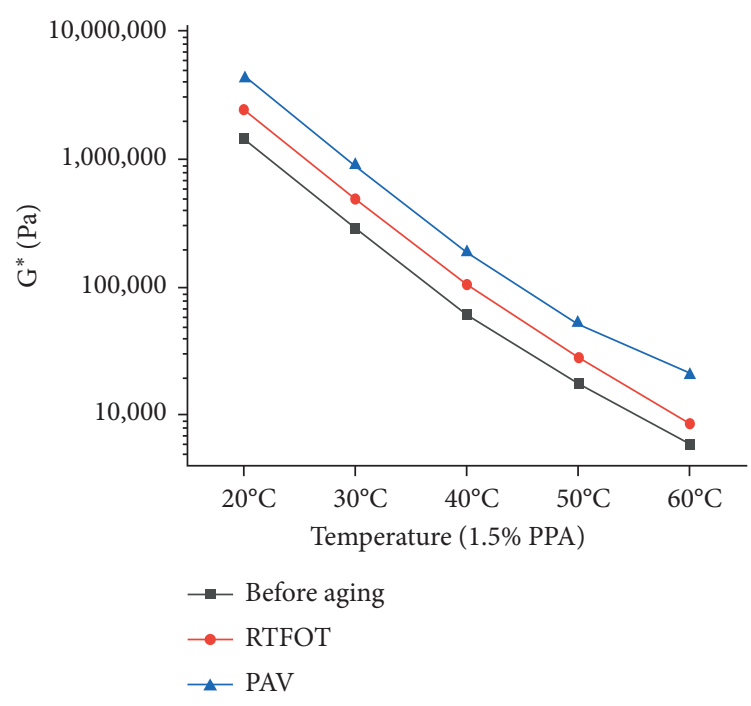

(b)

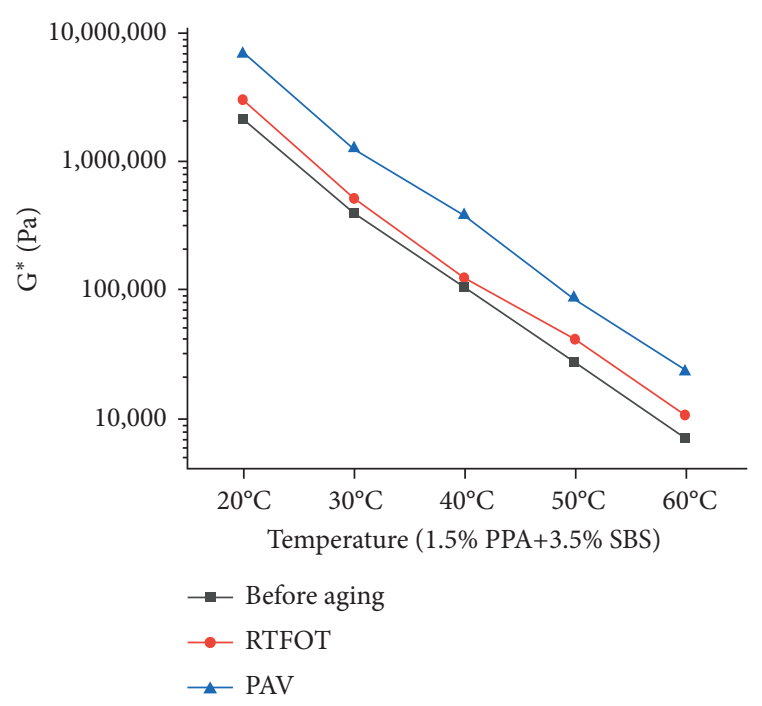

(d)

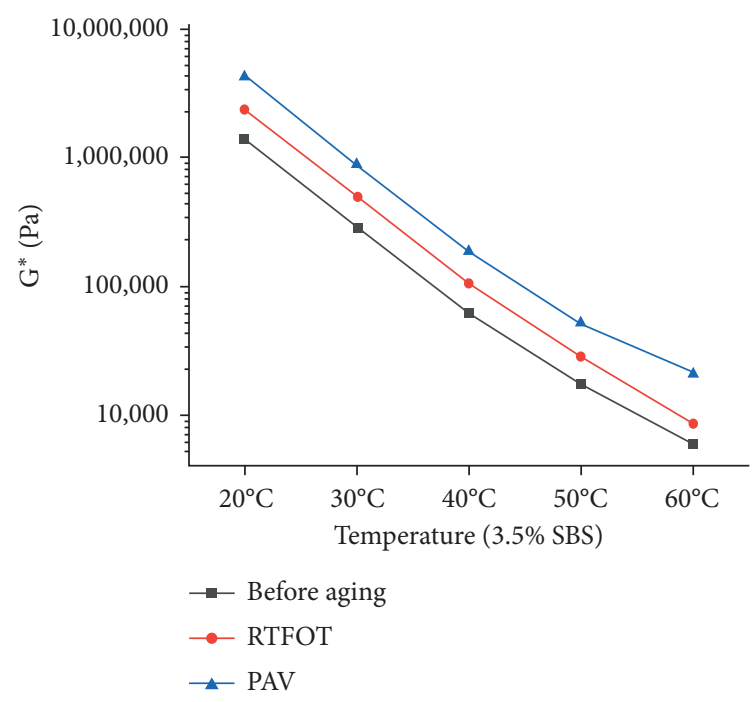

(e)

FIGURE 3: Variations of complex modulus at different aging levels. 
compositions of saturate, aromatic, resin, and asphaltene changed because of the internal and external factors: aromatics becoming resins and resins becoming asphaltenes [32-35]. The two modulus ratios after aging of PPA modified binder were slightly larger than SBS modified binder. SBS modifier was decomposed in the aging process, leading to the relatively smaller value of modulus. Besides, the modulus ratios after aging of PPA/SBS compound modified binder were between PPA and SBS polymer binders.

3.1.2. Effect of Aging on the Phase Angle. Phase angle can characterize the relative amount of viscous component and elastic component for a certain viscoelasticity material. When the phase angle is larger than $45^{\circ}$, the lagging period of strain phase will be longer than stress, and the proportion of viscous component of material will be larger [21, 36]. The results from Figure 4 showed that the phase angle of all selected samples decreased after two aging processes. This indicated that the proportion of viscous component decreased and elastic component increased after aging. Chemical reactions of volatilization and oxidation occurred in some components of asphalt binder during the period of the aging process.

During the aging procedure, the saturation of smaller molecular weight transformed to the colloid with larger molecular weight; then the colloid transformed to the asphaltene with larger molecular weight. However, asphaltene is solid at intermittent temperature, and colloid is semisolid. The outward manifestation of component transition is that the elastic component rises and the viscous component drops. At the same temperature, comparing with the phase angle data of five modified asphalts, $1.5 \mathrm{wt} \% \mathrm{PPA}$ modified asphalt was $2^{\circ}-5^{\circ}$ smaller than $3.5 \mathrm{wt} \%$ SBS after short-term aging and $2^{\circ}-6^{\circ}$ smaller than $3.5 \mathrm{wt} \%$ SBS after pressure aging. As the increase of temperature, the difference value of phase angle between $1.5 \mathrm{wt} \%$ PPA modified asphalt and $3.5 \mathrm{wt} \%$ SBS modified asphalt would be larger.

The analysis showed the elastic property of PPA modified asphalt would be better after aging. For SBS modified binder, there was the condensation of base asphalt and the degradation of SBS modifier during the aging process. Condensation increased the elastic component, but degradation removed a part of elastic component of SBS [37, 38]. Therefore, the phase angle of SBS modified asphalt was larger than PPA polymer asphalt after aging at a certain temperature, which can be attributed to a larger viscous component of SBS polymer binder. The phase angle of compound modified asphalt was between SBS and PPA modified asphalt. A larger dosage of PPA in the compound modified asphalt indicates a smaller phase angle after aging.

On the whole, the complex modulus of PPA modified asphalt was greater than that of SBS modified asphalt after aging, whereas the phase angle was smaller than SBS modified asphalt. Therefore, after the aging process, the antirutting property of PPA modified asphalt was better than SBS modified asphalt. Some studies have verified that PPA modifier can increase the high-temperature stiffness without notably sacrificing low-temperature performance of modified binders [39]. Adding PPA modifier to base asphalt makes the elastic component increased more than SBS modifier.

\subsubsection{Effect of Aging on the Viscoelasticity Proportion.} Figure 5 shows the ratio of storage modulus and loss modulus at multiple aging conditions for differing modified binders. The $G^{\prime}$ value is related to the stored energy in the elastic proportion of asphalt binder, whereas $G^{\prime \prime}$ value is pertaining to viscous part of energy dissipated as heat. The general trend is that the $G^{\prime} / G^{\prime \prime}$ ratio decreases with the increase of temperature, which can be contributed to the lower elastic proportion at higher temperature. Meanwhile, the aging of a certain binder generally led to the increase of $G^{\prime} / G^{\prime \prime}$, and this characteristic can be proven by the phase angle values in Figure 4. For the five modified binders, the storage modulus was larger than loss modulus at $20^{\circ} \mathrm{C}$ and $\mathrm{PAV}$ aging condition, indicating that lower temperature and harsh aging procedure were associated with less dissipating energy for a given binder. The $G^{\prime} / G^{\prime \prime}$ ratio larger than 1 was also tied to the phase shift below $45^{\circ}$. For modified binders shown in Figures 5(c) and 5(d), the difference of $G^{\prime} / G^{\prime \prime}$ ratio between RTFOT and unaged conditions was not significant, which can be attributed to the complex effect of PPA and SBS modifier.

3.1.4. Aging Ratio Analysis. The fatigue factor $G * \operatorname{Sin} \delta$ at intermittent temperature is indicative of dissipated energy for a certain strain amplitude. In general, a higher fatigue factor is associated with more dissipated strain energy, which can be attributed to premature damage subjected to the cyclic sinusoidal loading history (e.g., fatigue cracking). The aging ratio can be considered as a good indicator of modified binders' resistance to damage at intermittent temperature. Based on Figure 6, aging ratios at RTFOT aging level are smaller than one in most cases, whereas aging ratios at PAV aging level are within 2.0-4.0 for most polymer binders. This indicates that the 20-hour standard PAV procedure can induce more rigorous aging effect for polymer binders.

In general, the compound modification of PPA and SBS can effectively enhance the antiaging property for a given binder corresponding to a lower aging ratio. For SBS/PPA compound modified binder, the aging ratio is significantly smaller than PPA polymer binder in most cases. The aging ratio of $3.5 \mathrm{wt} \%$ SBS polymer binder is similar to that of compound modified binder. The aging ratio-based approach verifies SBS/PPA compound modification has a lower propensity to aging.

3.2. Link the GPC Results to Antiaging Property. In this work, GPC was utilized to characterize the molecular distribution rules for base asphalt modified by SBS and PPA. The purpose of this section is to understand the relationship between rheological investigation and chemical property of modified binders, further measuring the influence of polymer modification at different aging levels. 

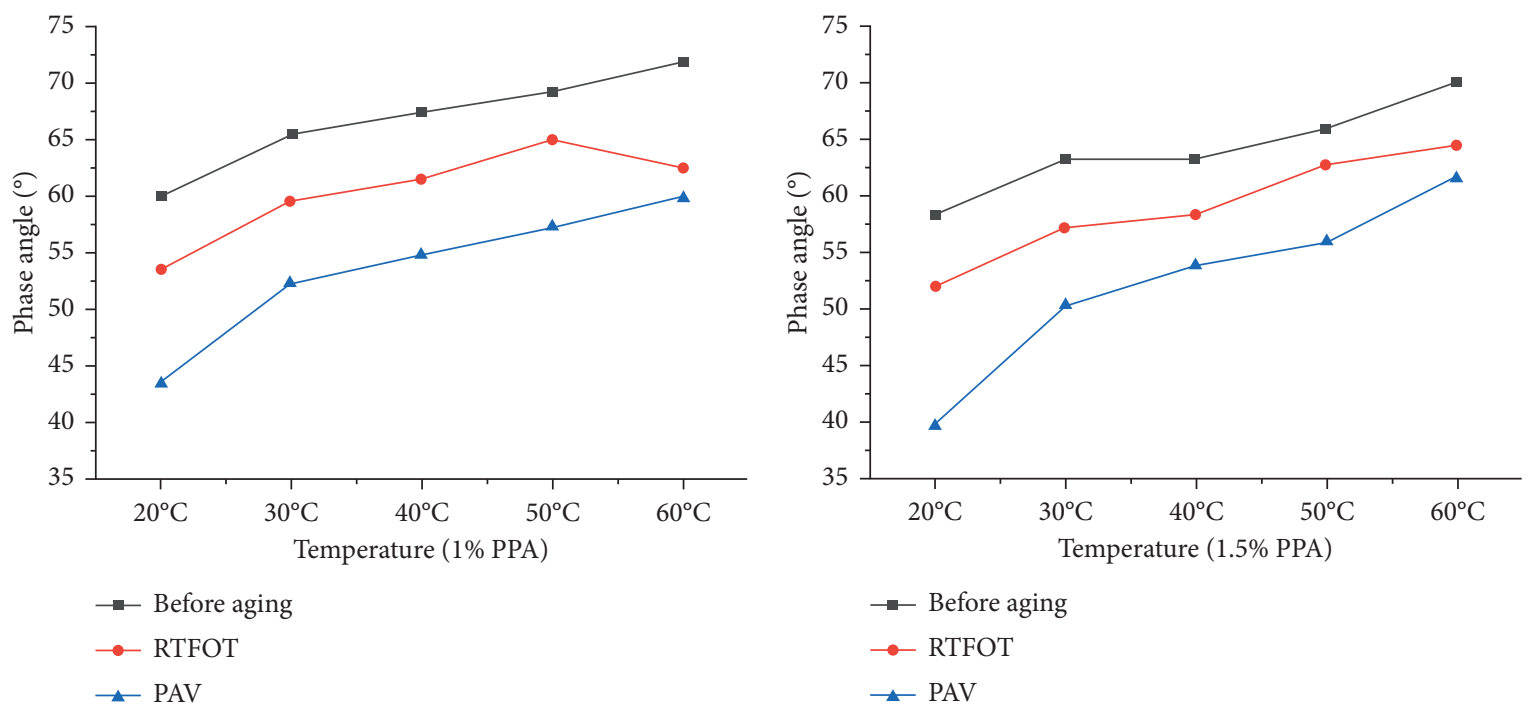

(a)

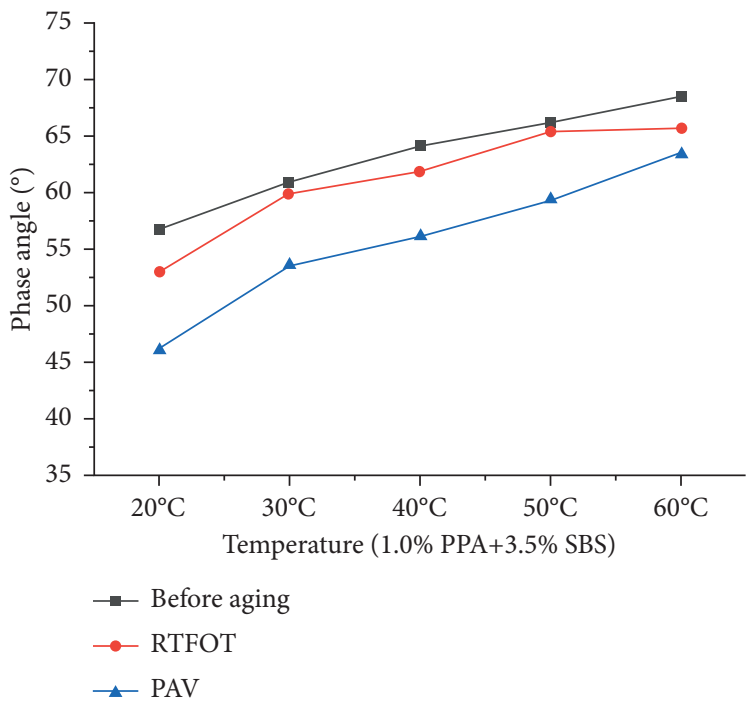

(b)

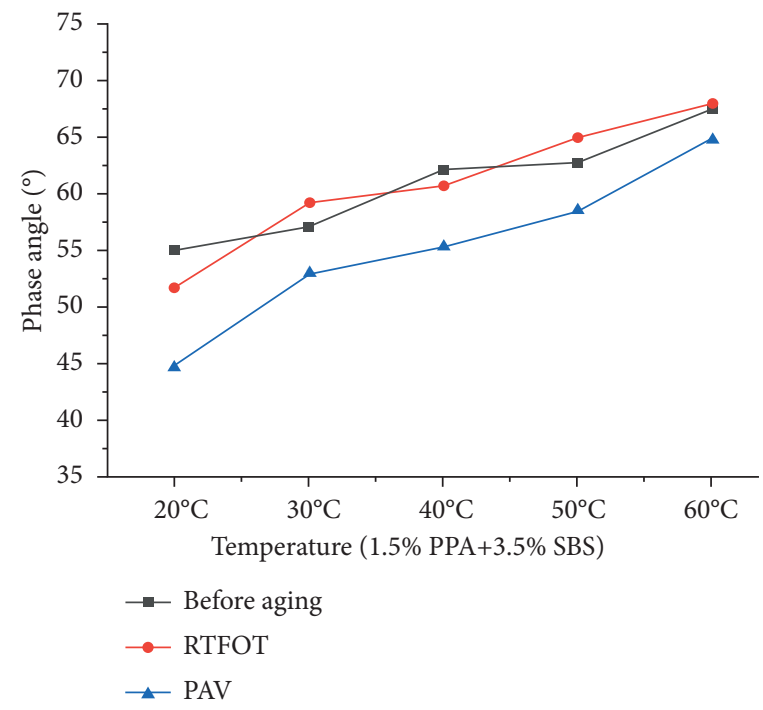

(c)

(d)

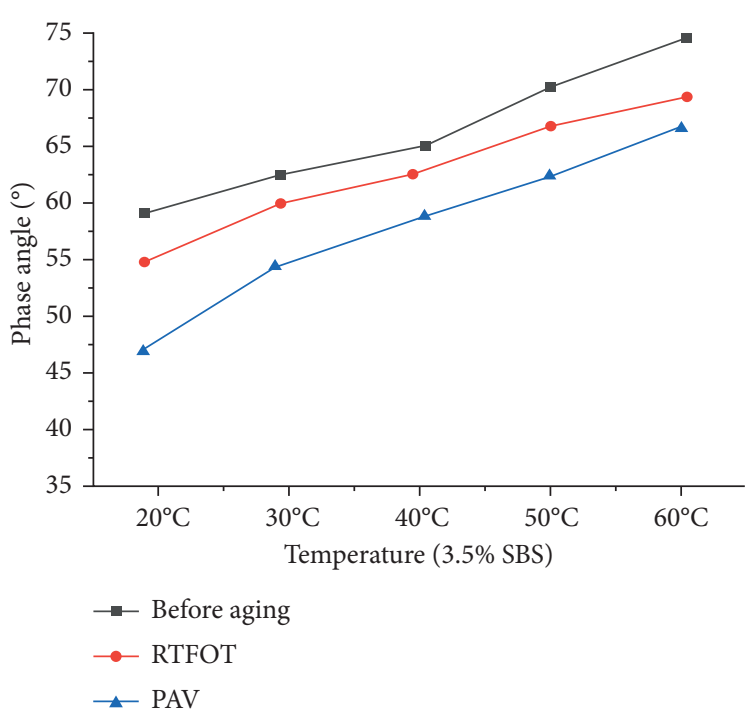

(e)

FIGURE 4: Variations of phase angle at different aging levels. 


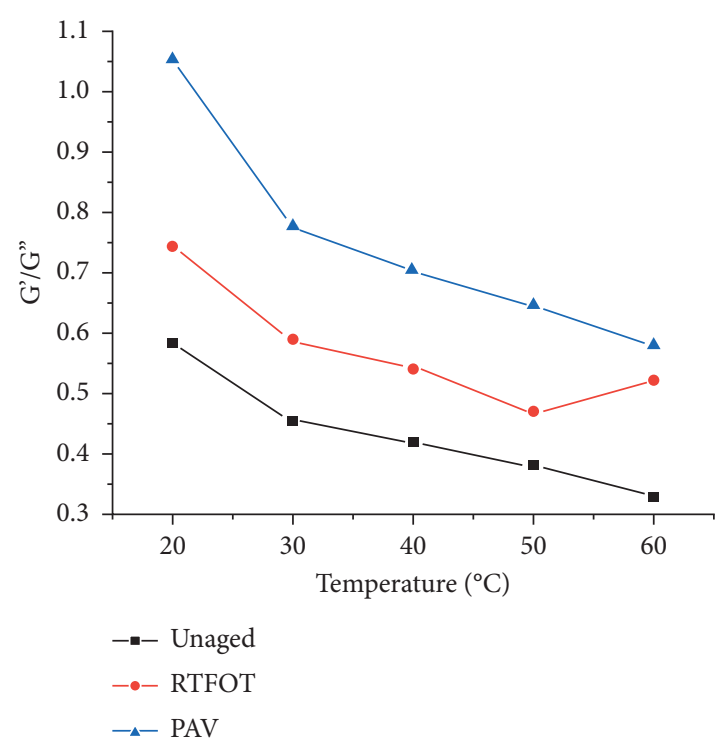

(a)

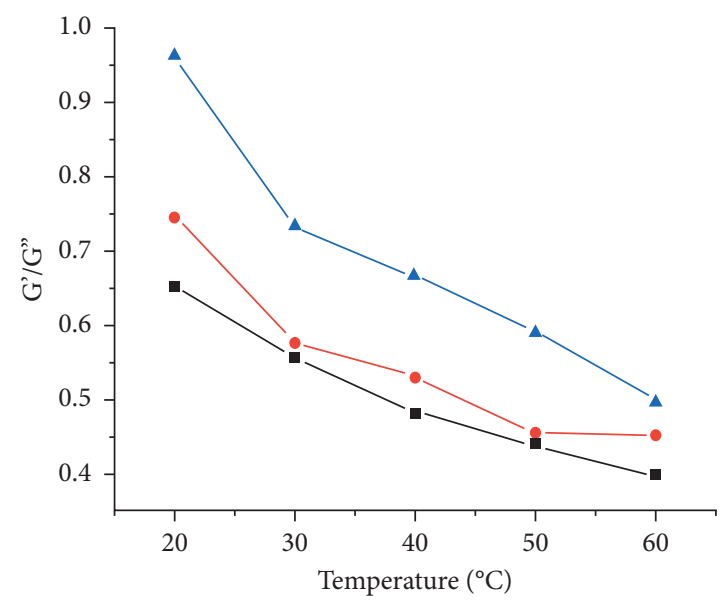

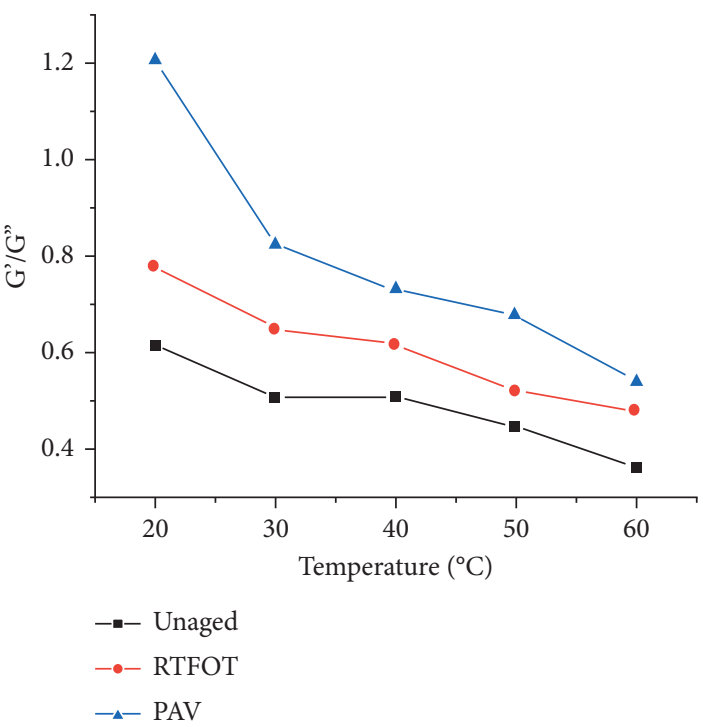

(b)

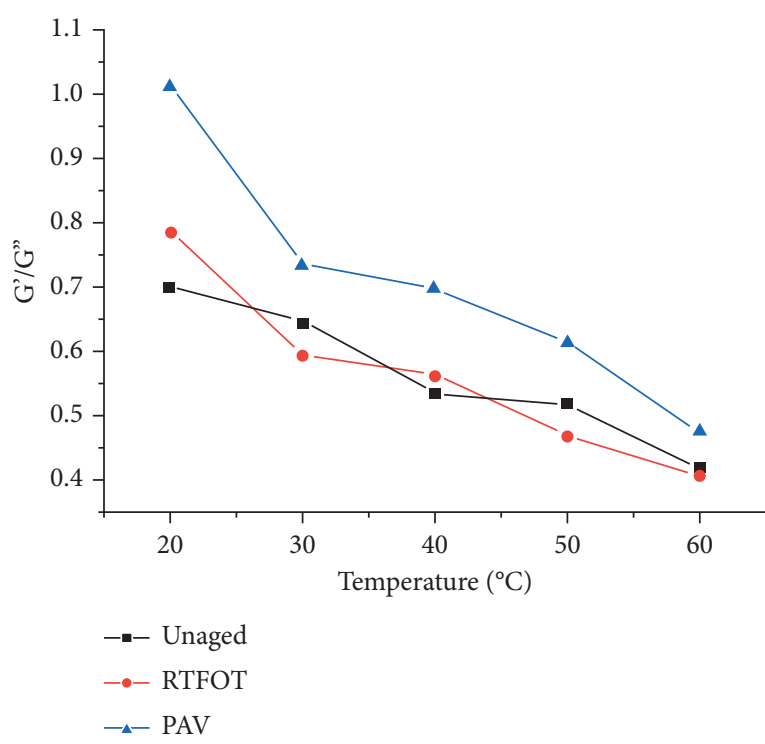

(d)

Figure 5: Continued. 


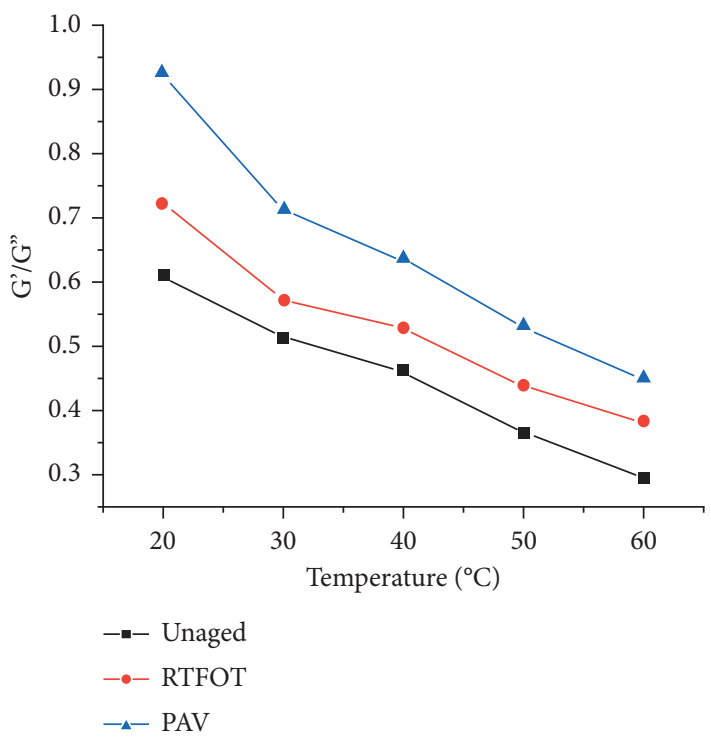

(e)

Figure 5: Effect of aging on the viscoelasticity proportion for binders of different dosages: (a) 1 wt $\%$ PPA, (b) 1.5 wt $\%$ PPA, (c) 1 wt $\%$ PPA + 3.5 wt $\%$ SBS, (d) $1.5 \mathrm{wt} \%$ PPA + $3.5 \mathrm{wt} \%$ SBS, and (e) $3.5 \mathrm{wt} \% \mathrm{SBS}$.

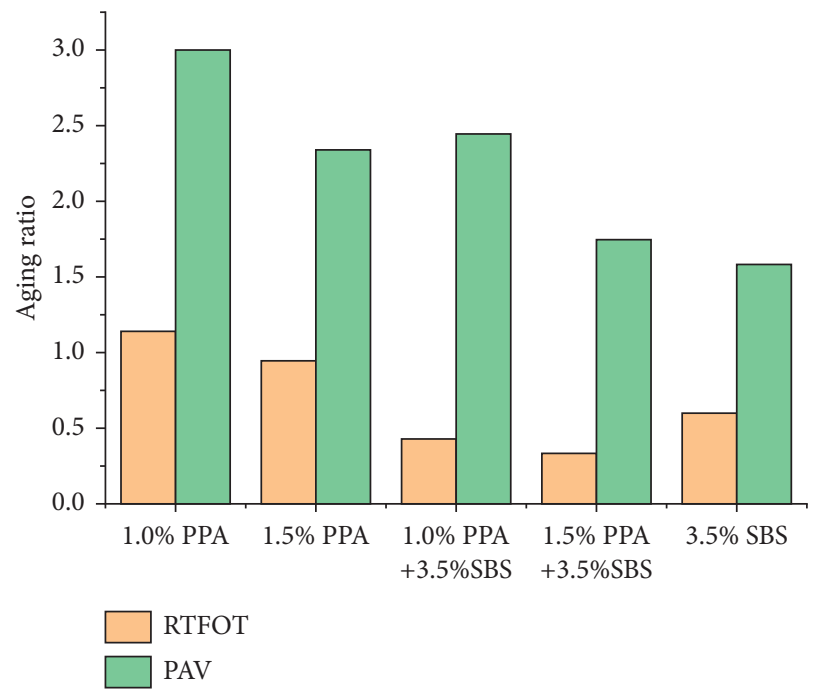

(a)

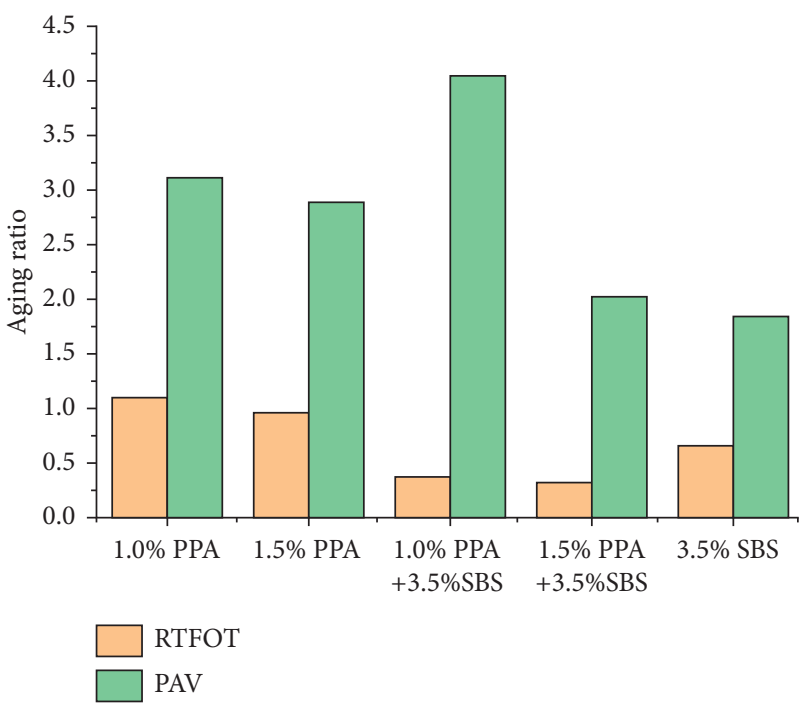

(b)

Figure 6: Continued. 


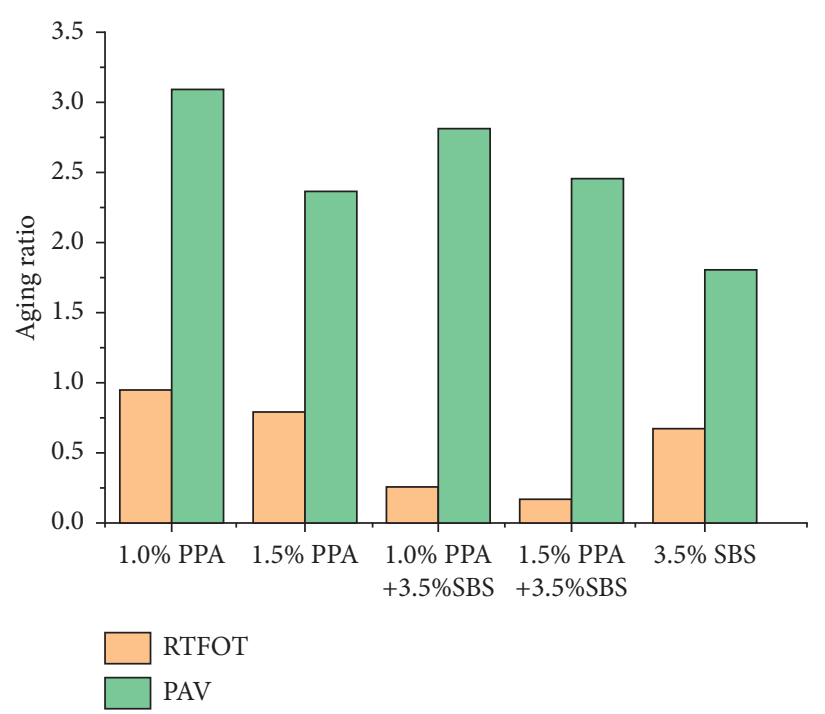

(c)

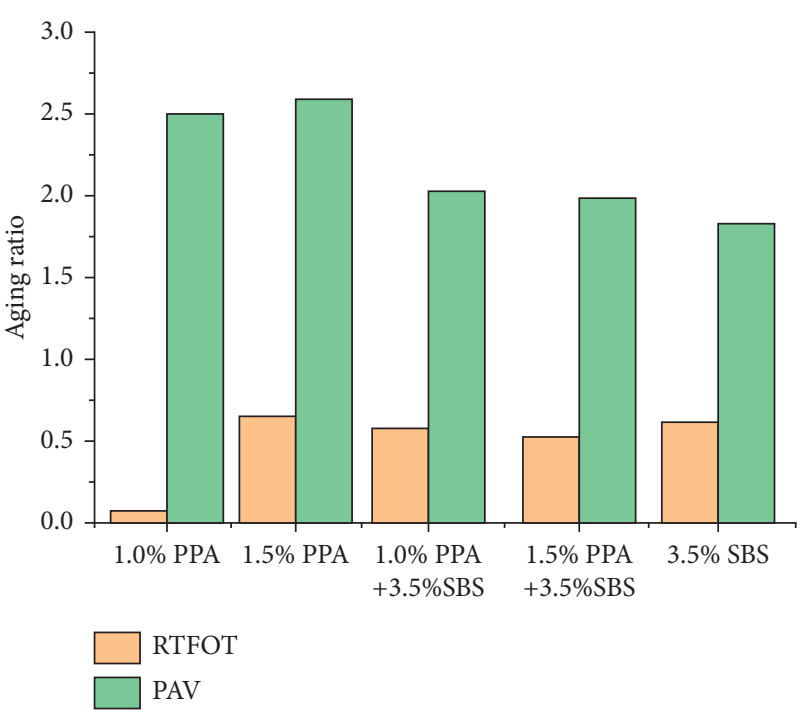

(d)

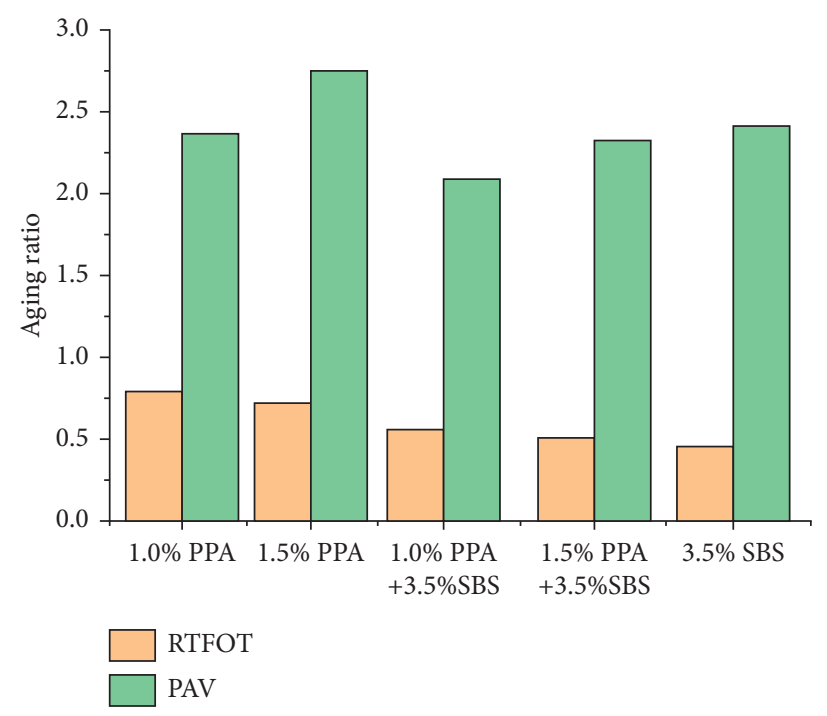

(e)

Figure 6: Aging ratio for polymer modified binders at different temperatures: (a) $20^{\circ} \mathrm{C}$, (b) $30^{\circ} \mathrm{C}$, (c) $40^{\circ} \mathrm{C}$, (d) $50^{\circ} \mathrm{C}$, and (e) $60^{\circ} \mathrm{C}$.

3.2.1. Analysis of GPC. For the five polymer binders, two absorption peaks appeared on gel permeation chromatography spectrogram, which belonged to SBS modifier phase and asphalt phase. Thus, analysis was conducted separately based on these two phases. The test results are shown in Figures 4 and 5.

The molecular weight $(\mathrm{Mw})$ of five asphalt increased significantly after aging in Figure 7(a). The naphthene and polar aromatics produce more asphaltenes after aging, and the increase in asphaltene leads to larger size of the asphaltene structure [40]. In Figure 7(a), the Mw of asphalt phase for compound modified asphalt increased relatively rapidly after aging. The $\mathrm{Mw}$ of all modified binders increased after the two aging processes and it indicated that the intermolecular force was enhanced during the aging procedure. In addition, strong intermolecular force made it difficult to generate relative displacement among molecules.
This characteristic holds the potential to improve the property of shearing deformation resistance. For compound modified asphalt, the molecular weight and intermolecular force were larger than individual PPA or SBS polymer binders at different aging levels. Meanwhile, the shearing deformation resistance of compound modified asphalt would be better, which could link to lower aging ratios mentioned in the previous section. For PPA modified asphalt, the molecular weight peak value $(\mathrm{Mp})$ increased after aging, whereas the Mp of SBS modified asphalt decreased, shown in Figures 7(d) and 8(d). The chemical reactions of two polymer binders were distinct during the aging procedure. Condensation of PPA modifier and degradation of SBS modifier occurred in the aging process of polymer binders. In general, more stable cross-linked network of polymer is associated with higher molecular weight for a given asphalt binder [41]. 


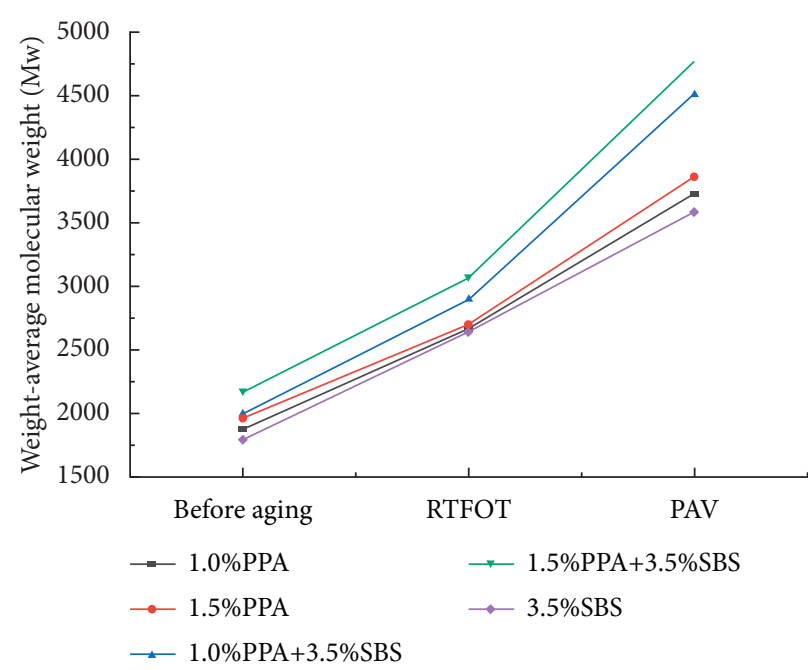

(a)

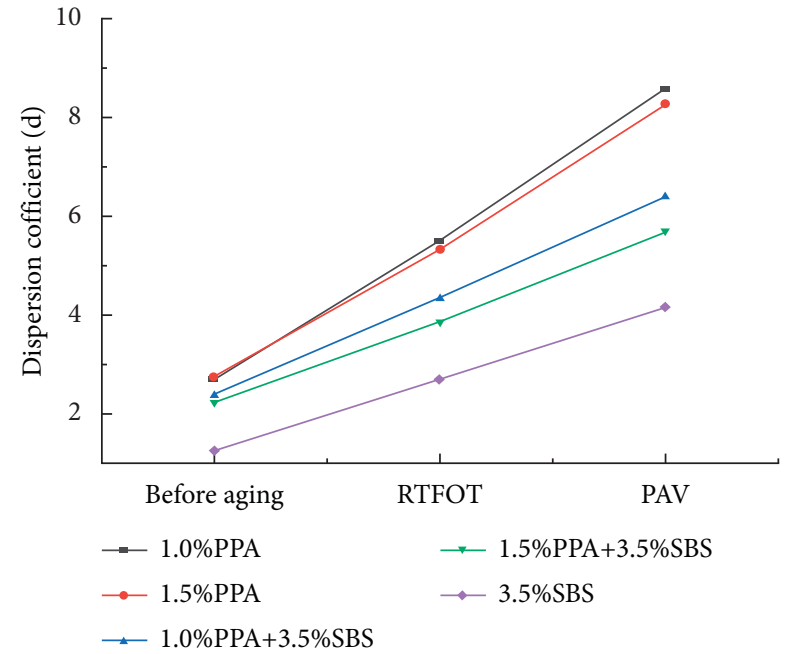

(c)

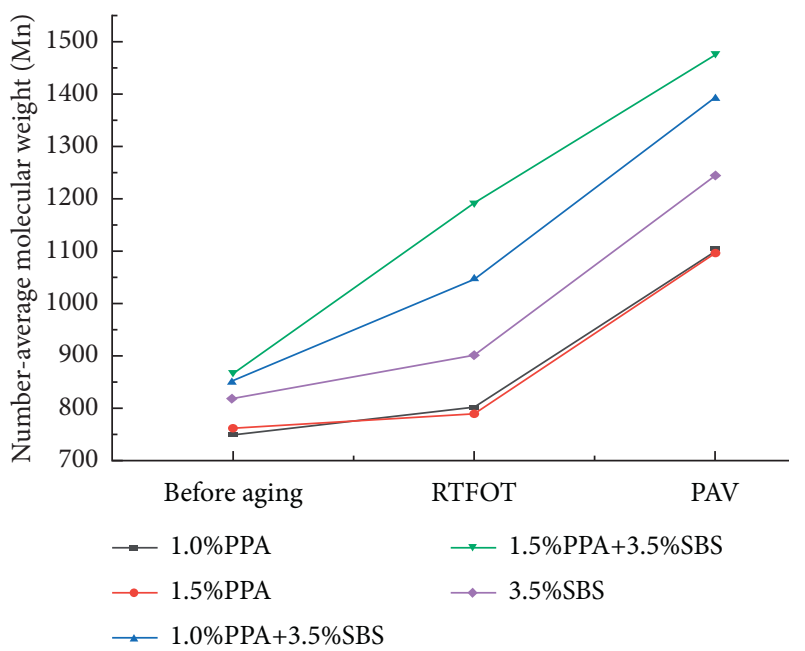

(b)

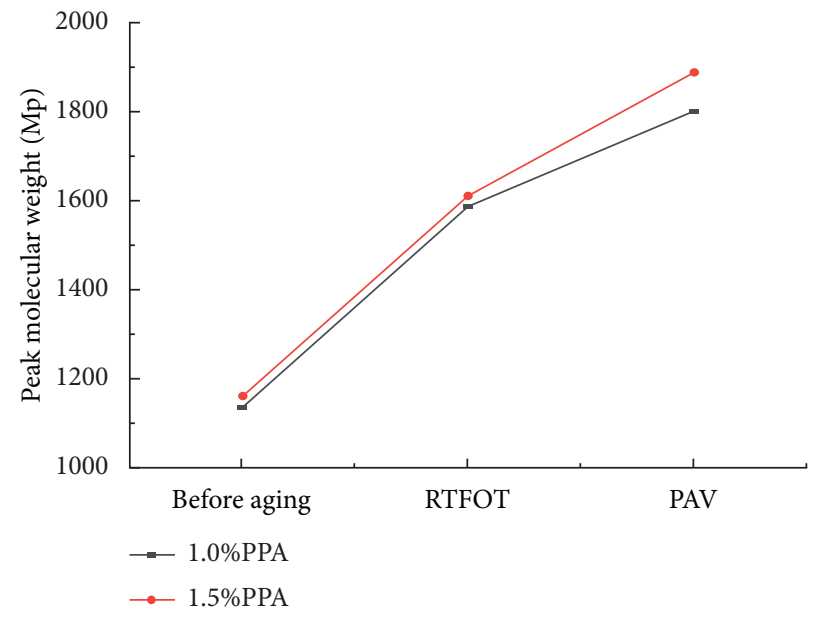

(d)

FIGURE 7: GPC results of modified asphalt phase. (a) Weight-average molecular weight (Mw). (b) Number-average molecular weight (Mn). (c) Dispersion coefficient (D). (d) Peak molecular weight (Mp).

Comparing with Figures 7(a) and 8(a), the Mw of SBS modifier phase was reduced after aging. Therefore, it can be considered that the aging procedure caused the degradation of SBS modifier, and the SBS modifier partially lost the elastic properties. This characteristic can account for the decrease of Mw for SBS modified asphalt after the aging process.

The dispersion coefficient (D) was utilized to characterize the degree of dispersion in the relative molecular weight [42]. The large dispersion coefficient indicated more dispersed molecular weight. In Figure 7(c), the dispersion coefficient of the asphalt phase was larger for the PPA modified asphalt. The chemical reaction of PPA modifier in the asphalt binder led to the increase of the asphaltene proportion. The molecular weight of asphaltene is the largest in the four SARA fractions. The dispersion coefficient of SBS and PPA polymer asphalt increased significantly, while the compound modified asphalt increased less. More dispersion occurred in the PPA polymer asphalt than the PPA/SBS compound modified asphalt. More dispersion of the asphaltenes in the maltene phase increased the compatibility of asphalt binder and hence increased its durability. Adding PPA modifier into base asphalt has the potential of improving the antiaging property for an aged binder. Previous studies showed that adding $1 \mathrm{wt} \%$ PPA modifier to a virgin asphalt binder increased the high-temperature performance grade $(\mathrm{PG})$ by around $10^{\circ} \mathrm{C}$ and the low-temperature PG by about $2^{\circ} \mathrm{C}$ [43]. 


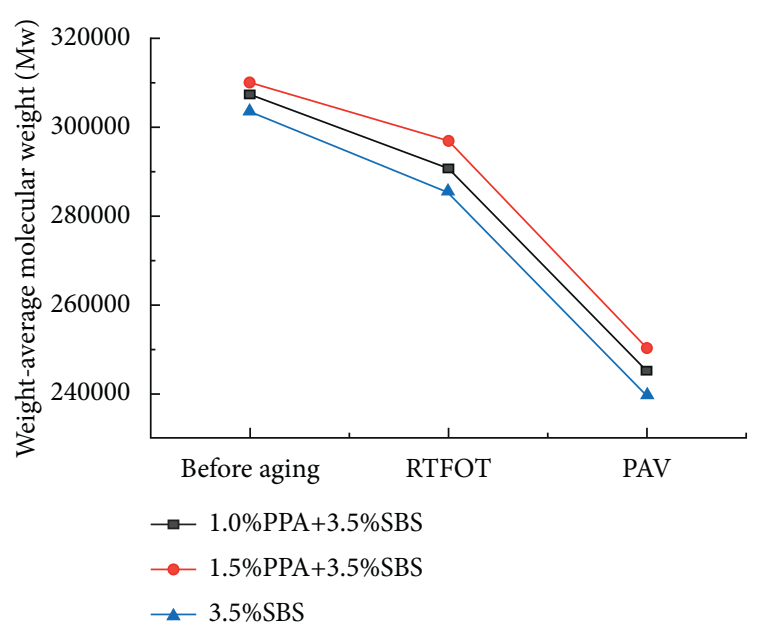

(a)

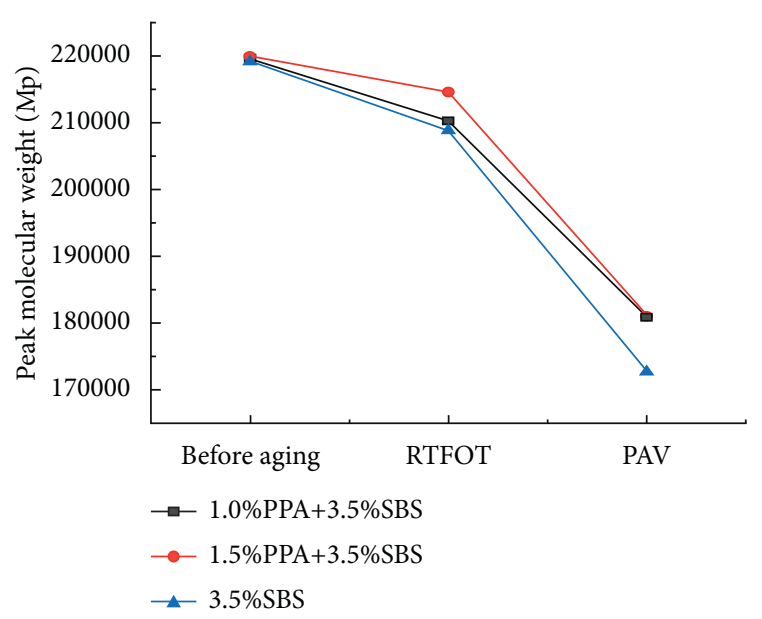

(c)

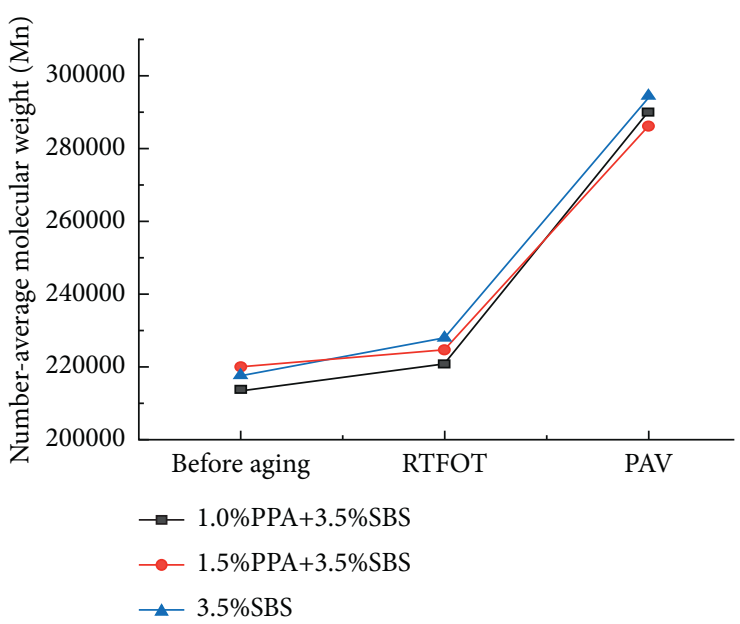

(b)

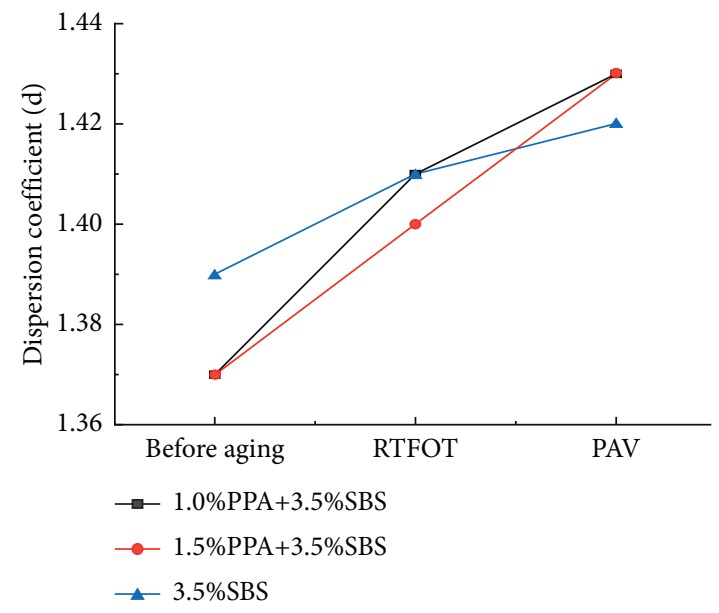

(d)

FIgURE 8: GPC results of SBS modifier phase. (a) Weight-average molecular weight (Mw). (b) Number-average molecular weight (Mn). (c) Peak molecular weight (Mp). (d) Dispersion coefficient (D).

\section{Conclusions}

In the research, the effect of PPA modifier on the rheological and molecular weight distribution was studied at different aging levels. RTFOT and PAV test were to evaluate the influence of different aging modes on the rheological parameters. GPC was selected to analyze the aging mechanism and molecular weight distribution of polymer binders with different dosages. The main conclusions can be summarized as follows:

(1) The complex modulus of five different modified asphalt increases significantly after RTFOT shortterm aging and PAV pressure aging. The complex modulus at intermittent temperature of $1.5 \mathrm{wt} \%$ PPA modified asphalt is greater than the other four modified asphalts, which can be attributed to the accelerated hardening effect of PPA modifier. The phase angle of the five modified asphalts decreases in the test after aging. The phase angle of PPA modified asphalt is extremely smaller than that of SBS modified asphalt. Changes of complex modulus and phase angle in the aging process indicate that hightemperature stiffness of PPA polymer binder increases more significantly after aging than other binders in this work. The PPA/SBS compound modified polymer binders appear to be less sensitive to oxidative aging, especially for short-term aging.

(2) The result of GPC shows that Mw, Mn, D, and Mp of asphalt phase increase in the aging process, whereas $\mathrm{Mn}$ and Mp of SBS modifier phase decrease. The Mw of asphalt phase for compound modified asphalt increases relatively rapidly. D of the selected five polymer binders increases significantly after aging, and compound modified asphalt increases less. The GPC parameters also verify the lower aging susceptibility of PPA/SBS compound polymer binders corresponding to higher molecular weight and lower dispersion coefficient.

(3) The future research can focus on establishing a reasonable test method and performance evaluation specification for PPA modified asphalt mixture. More theoretical explanations can be provided to the 
observed results in terms of oxidative aging chemistry, kinetics, and mechanisms and further link to the rheological properties. Further research is needed to investigate what happens at the molecular level when PPA or other modifiers are added. This study lays a foundation for the promotion and application of PPA modifier in the field of asphalt pavement.

\section{Data Availability}

The data used to support the findings of this study are included within the article.

\section{Conflicts of Interest}

The authors declare that there are no conflicts of interest regarding the publication of this article.

\section{Acknowledgments}

This work was sponsored by the National Key R\&D Program of China (Grant no. 2018YFE0103800) and Fundamental Research Funds for the Central Universities of Chang'an University (Grant no. 300102219316). The authors gratefully acknowledge their financial support.

\section{References}

[1] S.-P. Wu, L. Pang, L.-T. Mo, Y.-C. Chen, and G.-J. Zhu, "Influence of aging on the evolution of structure, morphology and rheology of base and SBS modified bitumen," Construction and Building Materials, vol. 23, no. 2, pp. 1005-1010, 2009.

[2] D. Kuang, B. Zhang, Y. Jiao, J. Fang, H. Chen, and L. Wang, "Impact of particle morphology on aggregate-asphalt interface behavior," Construction and Building Materials, vol. 132, pp. 142-149, 2017.

[3] F. Xiao, V. S. Punith, and S. N. Amirkhanian, "Effects of nonfoaming WMA additives on asphalt binders at high performance temperatures," Fuel, vol. 94, pp. 144-155, 2012.

[4] M. Guo and Y. Tan, "Interaction between asphalt and mineral fillers and its correlation to mastics' viscoelasticity," International Journal of Pavement Engineering, vol. 22, no. 1, pp. 1-10, 2021.

[5] S.-C. Huang, T. F. Turner, F. P. Miknis, and K. P. Thomas, "Long-term aging characteristics of polyphosphoric acidmodified asphalts," Transportation Research Record: Journal of the Transportation Research Board, vol. 2051, no. 1, pp. 1-7, 2008.

[6] R. Li, C. Wang, P. Wang, and J. Pei, "Preparation of a novel flow improver and its viscosity-reducing effect on bitumen," Fuel, vol. 181, pp. 935-941, 2016.

[7] M. Guo, H. Liu, Y. Jiao et al., "Effect of WMA-RAP technology on pavement performance of asphalt mixture: a state-of-theart review," Journal of Cleaner Production, vol. 266, Article ID 121704, 2020.

[8] D. Fee, R. Maldonado, G. Reinke, and H. Romagosa, "Polyphosphoric acid modification of asphalt," Transportation Research Record: Journal of the Transportation Research Board, vol. 2179, no. 1, pp. 49-57, 2010.

[9] R. Li, P. Wang, B. Xue, and J. Pei, "Experimental study on aging properties and modification mechanism of trinidad lake asphalt modified bitumen," Construction and Building Materials, vol. 101, pp. 878-883, 2015.

[10] I. Kodrat, D. Sohn, and S. A. M. Hesp, "Comparison of polyphosphoric acid-modified asphalt binders with straight and polymer-modified materials," Transportation Research Record: Journal of the Transportation Research Board, vol. 1998, no. 1, pp. 47-55, 2007.

[11] R. B. McGennis, "Implementation of polyphosphoric acid modification of asphalt binders and related experience: case study," Transportation Research Circular, vol. E-C160, pp. 136-149, 2012.

[12] P. De Filippis, C. Giavarini, and M. Scarsella, "Improving the ageing resistance of straight-run bitumens by addition of phosphorus compounds," Fuel, vol. 74, no. 6, pp. 836-841, 1995.

[13] R. Maldonaldo, M. Falkiewicz, G. Bazi, and K. Grzybowski, "Asphalt modification with polyphosphoric acid," in Proceedings of the Fifty-First Annual Conference of the Canadian Technical Asphalt Association (CTAA), Charlottetown, Canada, November 2006.

[14] D. Ge, K. Yan, L. You, and Z. Wang, "Modification mechanism of asphalt modified with sasobit and polyphosphoric acid (PPA)," Construction and Building Materials, vol. 143, pp. 419-428, 2017.

[15] R. McGennis and R. Clark, "Performance of acid modified pavements in AZ and NM," in Rocky Mountain Asphalt User Producer Group Meeting, N. M. Santa Fe, Ed., 2004.

[16] G. L. Baumgardner, J. Masson, J. R. Hardee, A. M. Menapace, and A. G. Williams, "Polyphosphoric acid modified asphalt: proposed mechanisms," Journal of the Association of Asphalt Paving Technologists, vol. 74, pp. 283-305, 2005.

[17] J. Y. M. Nuñez, M. D. I. Domingos, and A. L. Faxina, "Susceptibility of low-density polyethylene and polyphosphoric acid-modified asphalt binders to rutting and fatigue cracking," Construction and Building Materials, vol. 73, pp. 509-514, 2014.

[18] M. Jasso, R. Hampl, O. Vacin, D. Bakos, J. Stastna, and L. Zanzotto, "Rheology of conventional asphalt modified with SBS, elvaloy and polyphosphoric acid," Fuel Processing Technology, vol. 140, pp. 172-179, 2015.

[19] N. Baldino, D. Gabriele, F. R. Lupi, C. Oliviero Rossi, P. Caputo, and T. Falvo, "Rheological effects on bitumen of polyphosphoric acid (PPA) addition," Construction and Building Materials, vol. 40, pp. 397-404, 2013.

[20] G. D. Airey, "State of the art report on ageing test methods for bituminous pavement materials," International Journal of Pavement Engineering, vol. 4, no. 3, pp. 165-176, 2003.

[21] L. Xue, C. Zhang, J. Yu, S. Xu, L. Li, and W. Wu, "Investigation on thermo-oxidative aging properties of asphalt binder with hindered phenolic antioxidant," Journal of Testing and Evaluation, vol. 46, no. 2, pp. 624-630, 2017.

[22] Q. Qin, J. F. Schabron, R. B. Boysen, and M. J. Farrar, "Field aging effect on chemistry and rheology of asphalt binders and rheological predictions for field aging," Fuel, vol. 121, pp. 86-94, 2014.

[23] C. Ouyang, S. Wang, Y. Zhang, and Y. Zhang, "Improving the aging resistance of styrene-butadiene-styrene tri-block copolymer modified asphalt by addition of antioxidants," Polymer Degradation and Stability, vol. 91, no. 4, pp. 795-804, 2006.

[24] B. F. Bowers, B. Huang, X. Shu, and B. C. Miller, "Investigation of reclaimed asphalt pavement blending efficiency through GPC and FTIR," Construction and Building Materials, vol. 50, pp. 517-523, 2014. 
[25] Y. Wang, L. Sun, and Y. Qin, "Aging mechanism of SBS modified asphalt based on chemical reaction kinetics," Construction and Building Materials, vol. 91, pp. 47-56, 2015.

[26] G. Hao, W. Huang, J. Yuan, N. Tang, and F. Xiao, "Effect of aging on chemical and rheological properties of SBS modified asphalt with different compositions," Construction and Building Materials, vol. 156, pp. 902-910, 2017.

[27] C. Yan, W. Huang, P. Lin, Y. Zhang, and Q. Lv, "Chemical and rheological evaluation of aging properties of high content SBS polymer modified asphalt," Fuel, vol. 252, pp. 417-426, 2019.

[28] M. Guo, M. Liang, Y. Jiao et al., "A review of phase change materials in asphalt binder and asphalt mixture," Construction and Building Materials, vol. 258, Article ID 119565, 2020.

[29] G. Liu, E. Nielsen, J. Komacka, L. Greet, and M. V. D. Ven, "Rheological and chemical evaluation on the ageing properties of SBS polymer modified bitumen: from the laboratory to the field," Construction and Building Materials, vol. 51, pp. 244-248, 2014.

[30] H. Abedini, S. Naimi, and M. Abedini, "Rheological properties of bitumen emulsion modified with NBR latex," $P e$ troleum Science and Technology, vol. 35, no. 15, pp. 1576-1582, 2017.

[31] F. Kaseer, A. E. Martin, and E. Arámbula-Mercado, "Use of recycling agents in asphalt mixtures with high recycled materials contents in the United States: a literature review," Construction and Building Materials, vol. 211, pp. 974-987, 2019.

[32] W. D. Fernández-Gómez, H. Rondón Quintana, and F. Reyes Lizcano, "A review of asphalt and asphalt mixture aging: una revisión," Ingeniería e Investigación, vol. 33, no. 1, pp. 5-12, 2013.

[33] D. Swiertz, Asphalt Aging Characteristics, Rheological Implications and Laboratory Techniques, University of WisconsinMadison, Madison, WI, USA, 2010.

[34] F. A. Reyes, C. E. Daza, and H. A. Rondón, "Determination of SARA fractions of environmentally aged Colombian asphalts using liquid chromatography column," Revista EIA, vol. 17, pp. 47-56, 2012.

[35] J. C. Petersen, "A review of the fundamentals of asphalt oxidation: chemical, physicochemical, physical property, and durability relationships," Transportation Research Circular, vol. E-C140, 2009.

[36] C. Reddy, K. Babitha, and K. Biligiri, "Binder rheological relationships depicting wheel tracking rutting parameter for asphalt mixtures: a case study," Journal of Testing and Evaluation, vol. 45, no. 5, pp. 1870-1878, 2016.

[37] L. Xiang, J. Cheng, and S. Kang, "Thermal oxidative aging mechanism of crumb rubber/SBS composite modified asphalt," Construction and Building Materials, vol. 75, pp. 169-175, 2015.

[38] D. O. Larsen, J. L. Alessandrini, A. Bosch, and M. S. Cortizo, "Micro-structural and rheological characteristics of SBS-asphalt blends during their manufacturing," Construction and Building Materials, vol. 23, no. 8, pp. 2769-2774, 2009.

[39] S.-C. Huang, F. P. Miknis, W. Schuster, S. Salmans, M. Farrar, and R. Boysen, "Rheological and chemical properties of hydrated lime and polyphosphoric acid-modified asphalts with long-term aging," Journal of Materials in Civil Engineering, vol. 23, no. 5, pp. 628-637, 2011.

[40] Y. Li, R. Moraes, E. Lyngdal, and H. Bahia, "Effect of polymer and oil modification on the aging susceptibility of asphalt binders," Transportation Research Record: Journal of the Transportation Research Board, vol. 2574, no. 1, pp. 28-37, 2016.
[41] S. Liu, S. Zhou, and A. Peng, "Evaluation of polyphosphoric acid on the performance of polymer modified asphalt binders," Journal of Applied Polymer Science, vol. 137, no. 34, Article ID 48984, 2020.

[42] Y. Ding, B. Huang, X. Shu, Y. Zhang, and M. E. Woods, "Use of molecular dynamics to investigate diffusion between virgin and aged asphalt binders," Fuel, vol. 174, pp. 267-273, 2016.

[43] S. Ho, L. Zanzotto, and D. MacLeod, "Impact of chemical modification on the composition and properties of asphalt binders," in Proceedings of the Annual Conference-Canadian Technical Asphalt Association, pp. 153-170, Polyscience Publications; 1998, Toronto, Canada, November 2001. 